\title{
A Study of Red Blood Cell Indices among Covid 19 Individuals in Tertiary Care Triage Centre
}

\author{
A.Anitha ${ }^{1}$, P.Sudhakar ${ }^{2}$, S.Ramapriya ${ }^{3}$ \\ ${ }^{1}$ Professor, ${ }^{2}$ Assistant Professor, ${ }^{3}$ I year postgraduate, Department of Physiology, Chengalpattu Medical College, \\ Chengalpattu, Tamil Nadu, India
}

\begin{abstract}
Background: SARS-CoV-2 infection is characterized by the development and progression of inflammatory responses. The exploration of prognostic predictors for patients with COVID-19 is vital for prompt clinical intervention. Our study aims to explore the predictive value of hematological parameters in categorization of patients with COVID-19.We aimed to investigate associations between hematological parameters and disease severity in patients with SARS-CoV-2infection. The red blood cell distribution width (RDW), an indicator of anisocytosis has emerged as a potential tool for risk stratification of critically ill patients. Materials and Methods: Retrospective study after getting approval from Institutional ethics committee was performed with data obtained from triage OPD in Chengalpattu Medical College \& Hospital. The demographic, clinical, laboratory profile of COVID 19 positive patients who attended Triage OPD for a period of one month were collected. 3000 RT-PCR confirmed COVID positive patients of age group 20 to 70 years of both genders were included in the study. COVID 19 positive paediatric cases, antenatal and postnatal mothers, postoperative cases and sick cases admitted in COVID ICU were excluded from the study. Symptoms, associated co-morbidities and severity of COVID 19 were tabulated. Complete Blood Count measured by Automated Sysmex Analyser at the time of reporting to triage was noted. Red blood cell indices were analysed using SPSS 21.0 version. Results: There was statistically significant increase in RDW and decrease in MCV among patients with co-morbidity and severe illness compared to those with mild disease. There is no statistically significant difference in Red blood cell indices between patients with and without symptoms and patients without co-morbidities. Conclusion: RDW was found to be a screening tool to identify patients with severe COVID-19 and the results of this study suggest that RDW should be part of routine laboratory assessment and monitoring of COVID-19.
\end{abstract}

Key words: COVID severity, Red cell indices, $R D W$, Triage OPD.

\section{Introduction}

Corona virus disease 2019 (COVID-19) is asystemic viral infection presenting mostly asacuterespiratory illness with ahighrate of hospitalization and mortality. The emergence and rapid spread of the deadly COVID-

\section{Corresponding author:}

\section{Dr. S.Ramapriya.}

I year Post Graduate MD Physiology.

Department of Physiology. Chengalpattu medical

College and Hospital.

Email id: ramapriya.vim@gmail.com.

Mobile: 919600519878 19disease caused by severe acute respiratory syndrome coronavirus 2 (SARSCo2) is an evolving public health crisis worldwide. ${ }^{(1)}$

Covid-19 has significant impact onpulmonary, cardiovascular, renal, gastro intestinal, neurological and on hematopoietic system. The impact of Covid-19 disease on Immune system and hemostasis has been studied. Recent preliminary data following the Covid-19 out-break indicated an association of complete blood count $(\mathrm{CBC})$ parameters ${ }^{(2)}$ and coagulation profile (increased D-Dimer, fibrinogen and (FDP) with disease progression. $^{(3)}$ 
In the current COVID-19 scenario, it would be of utmost importance to explore if the most routine and cost-effective tests like CBC could serve as an aid in determining patient's clinical status. Emerging data raise the possibility that red blood cells (RBCs) might also be directly involved in the pathogenesis of the disease. An early report suggested that aprotein expressed on RBCs(CD147orBasigin) that serves as a receptor for plasmodium falciparum, might be an additional receptor for SARS-CoV-2 ${ }^{(4)}$. These findings led some clinicians to ask whether anemia has impact on COVID-19 patient outcome. Red blood cell indices like $\mathrm{MCH}, \mathrm{MCV}$, and $\mathrm{MCHC}$ are useful in the morphologic classification of anemias. Anemias are classified, according to the size of the red cell, as being normocytic, macrocytic or microcytic.

Anisocytosis is a biological condition characterized by circulating erythrocytes with pronounced volume heterogeneity (i.e., large, small, or both). This parameter is typically expressed as red blood cell distribution width (RDW) and can hence be calculated as the SD of the mean corpuscular volume (RDW-SD) or more frequently as the coefficient of variation of erythrocyte volumes (RDW-CV) as follows: $\mathrm{RDW}-\mathrm{CV}=\mathrm{SD}$ of erythrocyte volumes/mean corpuscular volume $\times 100$. RDW isused together with the mean corpuscular volume (MCV) in clinical practice to differentiate between causes of anemia. ${ }^{(5,6)}$ Increased RDW can be used as a tool for early diagnosis, as an inflammatory marker, and a mortality indicator in hypertensive, diabetic and other co-morbidpatients due to its close relation to inflammation.(7)

The red cell distribution width (RDW) of patients with severe COVID-19 increases significantly. The role of erythroid cell parameters as risk indicators has not been studied in detail yet. As the investigation in to the novel COVID-19 continues to grow, we aim to report that the Red blood cell indices of the new viral disease will provide useful information to the treating physicians. This study aim sat investigating the significant changes observed in the Red blood cell parameters among COVID-19 patients.

\section{Objectives}

1. To compare Red blood cell indices in COVID 19 positive patients with and without symptoms.

2.To compare Red blood cell indices in COVID 19 positive patients with and without co-morbidities.

3. To analyse the association of red cell indices with severity of disease.

\section{Materials and Methods}

This study was performed after getting approval from Institutional ethics committee with data obtained from triage OPD in Chengalpattu Medical College\& Hospital The demographic, clinical, laboratory characteristics of RT-PCR confirmed patients who attended Triage OPD for a period of one month was collected and informed consent was obtained from all patients involved in the present study. The venous blood samples were collected on the day of reporting at triage centre for Complete Blood Count (CBC).CBC was analyzed on fully automated 6 part hematology analyzer (Sysmex XN 1000) and the ratios were calculated from hematological parameters. The parameters were statistically analysed using SPSS 21.0 version. The normal distribution measurement was expressed by mean \pm standard deviation. The independent ' $t$ 'test was used to compare the mean softwogroups and we considered $\mathrm{P}<0.05$ asstatistically significant.

COVID 19 positive patients of age group 20 to 70 years of both genders were included in the study. COVID 19 positive paediatric cases, antenatal and postnatal mothers, postoperative cases and sick cases admitted in COVID ICU were excluded from the study.

Symptoms of COVID 19 such as fever, cough, sore throat, myalgia, diarrhoea, decreased sensation of smell were noted. Co-morbidities such as Type 2 Diabetes Mellitus, Hypertension, Coronary Artery Disease, Bronchial asthma, Tuberculosis, Epilepsy, Chronic Kidney Disease on Dialysis and other medical conditions documented were noted ${ }^{(8)}$ Severity of the disease was classified into mild, moderate and severe based on the symptoms and lung involvement. 
The patients were clinically categorised from the received data as,

1. Patients with symptoms and without symptoms.

2. Patients with co-morbidities \& without comorbidities.

3.Patients based on severity of disease.

In this study, severity was assessed by the presenting symptoms of the patient and lung involvement in the chest X-ray taken at the time of reporting. The number of mild, moderate and severe cases were 2662, 324 and 14 respectively. COVID19 severity was classified as follows;

1.Mild: without symptoms(2330) and very minimal symptoms with no lung involvement(332).

2. Moderate: Two or more symptoms and mild lung involvement(324).

3. Severe: Four or more symptoms with extensive lung involvement(14).

Tab.1; Normal values of Red blood cell indices-(9)

\begin{tabular}{|c|c|}
\hline Red blood cell Indices & Normal range \\
\hline Red Blood Cell (RBC) & $\begin{array}{c}\text { Male: } 4.5-6 \text { millions/cu.mm } \\
\text { Female: } 3.9-5.5 \text { millions/cu.mm }\end{array}$ \\
\hline Hemoglobin (Hb) & Male: $13-18 \mathrm{~g} / \mathrm{dl}$ \\
\hline Haematocrit (HCT) & Female: 12 - $16 \mathrm{~g} / \mathrm{dl}$ \\
\hline RDW-SD & Male: $40-52 \%$ \\
\hline RDW-CV & Female: $36-48 \%$ \\
\hline Mean Corpuscular Hemoglobin (MCH) & Male: $35.1-43.9 \mathrm{fl}$ \\
\hline Memale: 36.4 - $46.3 \mathrm{fl}$
\end{tabular}




\section{Results}

Results were analysed by Descriptive statistics, ' $t$ ' test and ANOVA.

Table No: 2 - Comparison of Red cell indices in patients with and without symptoms.

\begin{tabular}{|c|c|c|c|}
\hline \multirow{2}{*}{ Parameters } & $\begin{array}{c}\text { Without Symptoms } \\
\mathbf{n - 2 3 3 0}\end{array}$ & $\begin{array}{c}\text { With Symptoms } \\
\mathbf{n - 6 7 0}\end{array}$ & p value \\
\hline RBC & $4.52 \pm 0.61$ & $4.53 \pm 0.58$ & 0.705 \\
\hline HEMOGLOBIN & $13.01 \pm 4.75$ & $12.93 \pm 1.89$ & 0.669 \\
\hline HCT & $37.08 \pm 4.88$ & $37.08 \pm 4.78$ & 1.001 \\
\hline RDW-SD & $41.85 \pm 3.99$ & $41.86 \pm 3.87$ & 0.954 \\
\hline RDW-CV & $13.09 \pm 1.30$ & $13.12 \pm 1.46$ & 0.608 \\
\hline MCV & $82.57 \pm 6.69$ & $82.21 \pm 6.46$ & 0.216 \\
\hline MCH & $28.91 \pm 3.20$ & $28.68 \pm 3.37$ & 0.105 \\
\hline MCHC & $34.71 \pm 1.99$ & $34.69 \pm 1.83$ & 0.815 \\
\hline
\end{tabular}

Table No: 3 - Comparison of Red cell indices in patients with and without Co-morbidities.

\begin{tabular}{|c|c|c|c|}
\hline Parameters & $\begin{array}{c}\text { Without Co-morbidity } \\
\mathbf{n - 2 4 6 0}\end{array}$ & $\begin{array}{c}\text { With Co-morbidity } \\
\mathbf{n}-\mathbf{5 4 0}\end{array}$ & p value \\
\hline RBC & $4.37 \pm 0.60$ & $4.52 \pm 0.61$ & 0.454 \\
\hline HEMOGLOBIN & $13.27 \pm 4.64$ & $12.81 \pm 2.00$ & 0.069 \\
\hline HCT & $36.08 \pm 4.83$ & $36.88 \pm 5.00$ & 0.255 \\
\hline RDW-SD & $41.67 \pm 3.17$ & $42.21 \pm 3.75$ & $0.002^{*}$ \\
\hline RDW-CV & $13.12 \pm 1.20$ & $13.24 \pm 1.42$ & $0.042^{*}$ \\
\hline MCV & $82.78 \pm 6.66$ & $82.08 \pm 6.75$ & $0.052^{*}$ \\
\hline MCH & $28.86 \pm 3.21$ & $28.64 \pm 3.43$ & 0.072 \\
\hline MCHC & $34.77 \pm 1.99$ & $34.63 \pm 1.84$ & 0.133 \\
\hline
\end{tabular}


Table No: 4 - Relation between Red blood cell indices and severity of disease.

\begin{tabular}{|c|c|c|c|c|}
\hline \multirow{2}{*}{ Parameters } & \multicolumn{3}{|c|}{ Severity } & \multirow{2}{*}{ p value } \\
\hline & $\begin{array}{c}\text { Mild } \\
\text { n-2662 }\end{array}$ & $\begin{array}{c}\text { Moderate } \\
\text { n-324 }\end{array}$ & $\begin{array}{c}\text { Severe } \\
\text { n-14 }\end{array}$ & \\
\hline $\mathrm{RBC}$ & $4.52 \pm 0.61$ & $4.42 \pm 0.51$ & $4.31 \pm 0.15$ & 0.09 \\
\hline HEMOGLOBIN & $12.98 \pm 4.49$ & $12.76 \pm 1.91$ & $11.35 \pm 1.28$ & 0.263 \\
\hline HCT & $37.03 \pm 4.86$ & $36.78 \pm 4.85$ & $34.98 \pm 3.58$ & 0.215 \\
\hline RDW-SD & $41.82 \pm 4.28$ & $42.07 \pm 2.90$ & $45.16 \pm 2.43$ & $0.007^{*}$ \\
\hline RDW-CV & $13.12 \pm 1.34$ & $13.14 \pm 1.57$ & $14.18 \pm 0.87$ & $0.01 *$ \\
\hline $\mathrm{MCV}$ & $82.50 \pm 6.78$ & $82.67 \pm 5.81$ & $78.56 \pm 4.60$ & $0.008 *$ \\
\hline $\mathrm{MCH}$ & $28.88 \pm 3.29$ & $28.81 \pm 2.94$ & $27.41 \pm 2.98$ & 0.22 \\
\hline $\mathrm{MCHC}$ & $34.71 \pm 1.99$ & $34.75 \pm 1.71$ & $33.58 \pm 1.66$ & 0.09 \\
\hline
\end{tabular}

\section{Discussion}

In this cross-sectional study, 3000 patients with COVID-19 reported to triage centre at the tertiary care hospital were included. The mean age of study participants was $41.25 \pm 14.14$. Among them, $64.90 \%$ were males and $35.1 \%$ were females. This is consistent with studies done by Mukta et al ${ }^{(10)}$ in ESIC MC and hospital, Faridabad, India.

Among them, 2330 were asymptomatic (77.6\%) and 670 were symptomatic (22.4\%). The Meta analysis study of symptoms in COVID-19 patients showed cough $(38.50 \%)$, loss of taste/smell $(11.79 \%)$, fever $(10.59 \%)$, sore throat $(2.53 \%)$ as the major symptoms followed by breathlessness (1.94\%) and gastro intestinal symptoms(2.23\%). Further, $29.55 \%$ had two to three symptoms and $2.83 \%$ presented with more than four symptoms at the time of reporting. Some are asymptomatic during full course of disease ${ }^{(11)}$

Table 2 shows there was no statistically significant difference in hematological parameters between symptomatic and asymptomatic patients. The probable reason could be that some study participants would have reached triage OPD at the onset of symptoms while some at the later stage of disease. Further, those patients without symptoms were not followed up and this has been also observed in studies done by R.E.A. Santos et al.

In Table 3; 82\% were identified without any co-morbidity and $12 \%$ were with co-morbidity. We identified statistical differences in hematological parameters like RDW-SD(0.002), RDW-CV(0.0042), $\mathrm{MCV}(0.052)$ associated with co-morbid patients which is consistent with the study of Bilal et al ${ }^{(12)}$ 
The abnormalities of RDW and MCV observed in patients with co-morbidities in this study are explained by the inability of the bone marrow to produce functionally effective RBCs. Due to inadequate RBCs, the ability to carry oxygen is affected, which makes gaseous exchange difficult resulting in breathing difficulty in these patients. Along with the lung involvement by Corona virus, these abnormalities of RBCs alsoexplains the symptoms of dyspnea (1.94\%) observed in the COVID patients of the present study. On the other hand, the presence of comorbid conditions of these patients might interfere with $\mathrm{RBC}$ production due to existing inflammation. ${ }^{(13)}$

\section{$R D W$ in inflammation;}

An elevated RDW, a marker of anisocytosis has been implicated in a wide spectrum of diseases, particularly in patients with non-specific ARDS and also observed in diseases associated with acute and chronic inflammation. RDW as a marker of pre-existing, pro-inflammatory or chronic inflammatory state can be used as a predictor of COVID 19 disease progression. Inflammation plays a major role in the pathogenesis and severity of COVID 19 disease, culminating in cytokine release syndrome (CRS) or cytokine storm in its most severe form. ${ }^{(14,15)}$ The inflammatory cytokines may induce profound alterations in the behavior of hematopoietic cells, mainly neutrophils, lymphocytes and monocytes and red blood cells. Neutrophil counts were significantly higher and lymphocytes were decreased in covid-19 patients with severe disease. This may be linked to persistent infection and prolonged hypoxia leading to release of more granulocytes as a compensatory mechanism by the bone marrow. These results are consistent with the findings of Chen et al. ${ }^{(16)}$ However, the particular mechanism for altered RDW with SARS-COV-2 is still under evaluation. Sarkar et al ${ }^{(14)}$ studied the relationship between elevated RDW with the severity in COVID-19 patients to predict the mortality of the disease. The presence of a sustained inflammatory state could trigger and sustain the marked anisocytosis observed in COVID-19 patients with severe illness in our study.

\section{Red blood cell morphology in COVID,}

Erythrocyte biology is strongly dependent on iron metabolism, and many inflammatory conditions are associated with markedly elevated erythrocyte size variability and impaired erythropoiesis with accelerated release of larger RBCs into the circulation, as well as oxidative erythrocyte injury, which would ultimately impair their flexibility, size, and morphology of red blood cells $^{\left({ }^{(17)} I t\right.}$ has been reported that before aggravation of infection symptoms, the level of oxidative stress in the body increases significantly, and the release of oxygen free radicals increases. Also, insufficient circulating nutrients in patients may lead to an increase in $\mathrm{RBC}$ membrane instability, increasing RDW. All these factors might cause an increase in RDW and a decrease in $\mathrm{MCV}$ in severely ill patients.(18)

While a recent study reported that the structural change of lipids and proteins in the membrane of circulating RBCs is due to SARSCoV-2 infection and there are also reports of bone marrow injury secondary to SARS-CoV-2 infection. The development of micro-and macro-thrombi, due to intravascular coagulopathy which is commonly seen in critically ill COVID-19 patients leads to erythrocyte injury resulting in morphological abnormalities and large size heterogeneity within the circulation which implies elevated RDW. ${ }^{(19)}$

Table 4 shows significant increase in RDW-SD, RDW-CV and decrease in MCVin patients with severity of disease, which is similar to the study done by Wang et al. ${ }^{(18)}$. Also, Zinellu \& Mangoni et $\mathrm{al}^{(20)}$ found that the severely ill COVID-19 patients had significantly elevated RDW in comparison to the patients without severity which is also consistent with our study, that the elevated RDW is associated with disease severity.

\section{Conclusion}

The present study shows the abnormalities of RDW in severely ill Covid19 patients, which is consistent with the study of Lippi et $\mathrm{al}^{(7)}$. There is increase in RDW and decrease in MCV among COVID 19 patients with disease severity. ${ }^{(18)}$ Clinicians should consider 
theseparameterswhenreadingtheCBCofCOVID-19 patients. The results of this study support the use of RDW for assessing the risk of severity in COVID 19 progression.

Limitations of the study: Red blood cell indices at the time of reporting were only taken into account. Follow up of patients and monitoring of red blood cell indices could have given a clear picture regarding their role in COVID 19.

Implications: This study emphasize that evaluation of red blood cell indices can also be used as a screening tool asNLR, platelet and lymphocyte count interpretation in COVID 19.

Ethical Committee Clearance: Taken from Institutional Ethics Committee, Chengalpattu Medical College.

Financial Support: None

Conflict of Interest: None.

\section{References}

1. Lin S, Mao W, Zou Q, Lu S, Zheng S. Associations between hematological parameters and disease severity in patients with SARS-CoV-2 infection. J Clin Lab Anal [Internet]. 2021 Jan [cited 2021 Jul 24];35(1). Available from: https://onlinelibrary. wiley.com/doi/10.1002/jcla.23604

2. Fan BE, Chong VCL, Chan SSW, Lim GH, Lim KGE, Tan GB, et al. Hematologic parameters in patients with COVID-19 infection. Am J Hematol. 2020 Jun;95(6):E131-4.

3. Han H, Yang L, Liu R, Liu F, Wu K, Li J, et al. Prominent changes in blood coagulation of patients with SARS-CoV-2 infection. Clin Chem Lab Med CCLM. 2020 Jul 1;58(7):1116-20.

4. Crosnier C, Bustamante LY, Bartholdson SJ, Bei AK, Theron M, Uchikawa M, et al. BASIGIN is a receptor essential for erythrocyte invasion by Plasmodium falciparum. Nature. 2011 Nov 9;480(7378):534-7.

5. Constantino BT. Red Cell Distribution Width, Revisited. Lab Med. 2013 May 1;44(2):e2-9.
6. Nada AM. Red cell distribution width in type 2 diabetic patients. Diabetes Metab Syndr Obes Targets Ther. 2015;8:525-33.

7. Lippi G, Henry BM, Sanchis-Gomar F. Red Blood Cell Distribution Is a Significant Predictor of Severe Illness in Coronavirus Disease 2019. Acta Haematol. 2021;144(4):360-4.

8. Sanyaolu A, Okorie C, Marinkovic A, Patidar R, Younis K, Desai P, et al. Comorbidity and its Impact on Patients with COVID-19. Sn Compr Clin Med. 2020 Jun 25;1-8.

9. Lokwani DP. The ABC of CBC: Interpretation of Complete Blood Count and Histograms. JP Medical Ltd; 2013. 198 p.

10. Pujani M, Raychaudhuri S, Verma N, Kaur $\mathrm{H}$, Agarwal S, Singh M, et al. Association of Hematologic biomarkers and their combinations with disease severity and mortality in COVID-19an Indian perspective. :11.

11. Santos REA, da Silva MG, do Monte Silva MCB, Barbosa DAM, Gomes AL do V, Galindo LCM, et al. Onset and duration of symptoms of loss of smell/taste in patients with COVID-19: A systematic review. Am J Otolaryngol. 2021 Mar 1;42(2):102889.

12. Bilal A, Farooq JH, Kiani I, Assad S, Ghazanfar H, Ahmed I. Importance of Mean Red Cell Distribution Width in Hypertensive Patients. Cureus [Internet]. 2016 Nov 29 [cited 2021 Jul 24]; Available from: http://www.cureus.com/articles/5862importance-of-mean-red-cell-distribution-widthin-hypertensive-patients

13. Blood routine test in mild and common 2019 coronavirus (COVID-19) patients., Bioscience Reports - X-MOL [Internet]. [cited $2021 \mathrm{Jul}$ 24]. Available from: https://www.X-mol.com/ paper/1294263504040763392?adv

14. Sarkar S, Kannan S, Khanna P, Singh AK. Role of red blood cell distribution width, as a prognostic indicator in COVID-19: A systematic review and meta-analysis. Rev Med Virol. 2021 Jun 6;e2264.

15. Tay MZ, Poh CM, Rénia L, MacAry PA, Ng LFP. The trinity of COVID-19: immunity, inflammation and intervention. Nat Rev Immunol. $2020 \mathrm{Apr}$ 28;1-12. 
16. Chen G, Wu D, Guo W, Cao Y, Huang D, Wang $\mathrm{H}$, et al. Clinical and immunological features of severe and moderate coronavirus disease 2019. J Clin Invest. 2020 Apr 13;130(5):2620-9.

17. Salvagno GL, Sanchis-Gomar F, Picanza A, Lippi G. Red blood cell distribution width: A simple parameter with multiple clinical applications. Crit Rev Clin Lab Sci. 2015 Mar 4;52(2):86-105.

18. Wang C, Zhang H, Cao X, Deng R, Ye Y, Fu Z, et al. Red cell distribution width (RDW): a prognostic indicator of severe COVID-19. Ann Transl Med. 2020 Oct;8(19):1230.
19. Henry BM, Benoit JL, Benoit S, Pulvino C, Berger BA, Olivera MHS de, et al. Red Blood Cell Distribution Width (RDW) Predicts COVID-19 Severity: A Prospective, Observational Study from the Cincinnati SARS-CoV-2 Emergency Department Cohort. Diagn Basel Switz. 2020 Aug 21;10(9):E618.

20. Zinellu A, Mangoni AA. Red Blood Cell Distribution Width, Disease Severity, and Mortality in Hospitalized Patients with SARSCoV-2 Infection: A Systematic Review and MetaAnalysis. J Clin Med. 2021 Jan 14;10(2):286. 